\title{
Clinical Outcomes of 42 Renal Cell Carcinoma Patients With Metastases Solely to the Lung Who Received Sorafenib as Second-line Systemic Therapy
}

\author{
HIDEAKI MIYAKE, YUTO MATSUSHITA, HIROMITSU WATANABE, KEITA TAMURA, \\ DAISUKE MOTOYAMA, TOSHIKI ITO, TAKAYUKI SUGIYAMA and ATSUSHI OTSUKA \\ Department of Urology, Hamamatsu University School of Medicine, Hamamatsu, Japan
}

\begin{abstract}
Background/Aim: In renal cell carcinoma (RCC), sorafenib was the first targeted agent demonstrating a definitive benefit in a large phase III clinical trial. The objective of this study was to assess the clinical outcomes of 42 consecutive RCC patients with metastases solely to the lung who received sorafenib as a second-line systemic agent. Patients and Methods: Of the 42 patients, 14 (33.3\%) and 28 (66.7\%) received cytokine therapy and sunitinib, respectively, prior to treatment with sorafenib. In this series, all patients initially received $400 \mathrm{mg}$ of sorafenib twice daily on a continuous dosing schedule. The efficacy and safety of secondline sorafenib in these 42 patients were retrospectively evaluated. Results: As the best response to sorafenib, 2 (4.8\%), $14(33.3 \%), 22(52.4 \%)$ and $4(9.5 \%)$ patients were judged to show a complete response, partial response, stable disease and progressive disease, respectively. The median progression-free survival (PFS) and overall survival (OS) after the introduction of sorafenib was 10.6 and 30.2 months, respectively. Multivariate analyses of several parameters identified the following independent prognostic predictors: $C$-reactive protein (CRP) level for PFS, and International Renal Cell Carcinoma Database Consortium classification and CRP level for OS. The common adverse events associated with sorafenib were handfoot syndrome, hypertension and diarrhea, which developed in $22(52.4 \%), 17(40.5 \%)$ and $13(31.0 \%)$, respectively; however, any AEs corresponding to $\geq$ grade 3 occurred in only 16 (38.1\%). Conclusion: Favorable disease control with acceptable tolerability might be expected by introducing sorafenib as second-line therapy for RCC patients with
\end{abstract}

Correspondence to: Hideaki Miyake, Department of Urology, Hamamatsu University School of Medicine, 1-20-1 Handayama, Higashi-Ku, Hamamatsu 431-3192, Japan. Tel: +81 534352306, Fax: +81 534352305; e-mail: hideakimiyake@ hotmail.com

Key Words: Sorafenib, lung metastases, renal cell carcinoma, second-line therapy. metastases solely to the lung; therefore, sorafenib could be the optimal option for this category of patients.

In recent years, several types of molecular-targeted agent, developed based on intensive investigations of the precise mechanisms mediating the progression of renal cell carcinoma ( $\mathrm{RCC}$ ), have been introduced into routine clinical practice, resulting in marked improvement of the clinical outcomes of patients with metastatic RCC (mRCC) compared with that in the era of cytokine therapy (1). In the majority of $\mathrm{mRCC}$ patients, however, targeted therapies will ultimately fail, and a wide variety of adverse events (AEs) occur in a significant proportion of patients treated with targeted agents; therefore, it is very important to conduct sequential treatment using multiple agents under the optimal control of AEs in order to further prolong the survival of these patients $(2,3)$.

Sorafenib, an orally available tyrosine kinase inhibitor (TKI), has been shown to exert its antitumor activity by mainly blocking the angiogenesis of tumor tissues (4). In mRCC, sorafenib was the first targeted agent demonstrating a definitive benefit in a large phase III clinical trial. This trial randomized $>900$ advanced RCC patients previously receiving cytokine therapy into either a sorafenib or placebo arm, and showed a significant difference in the progressionfree survival (PFS) between these two groups, favoring the sorafenib group with a reduction in the risk of disease progression of $56 \%$ (5). Furthermore, the favorable activity and tolerability of sorafenib were also suggested by the outcomes of expanded access programs $(6,7)$.

A few years later, however, other TKIs, sunitinib and pazopanib, achieved positive results in pivotal clinical trials, targeting treatment-naïve mRCC patients $(8,9)$. In addition, another TKI, axitinib, was reported to lead to a significant benefit in terms of PFS compared to sorafenib in mRCC patients who failed first-line systemic therapy (10). Accordingly, sorafenib has not been widely used as either a first- or second-line agent for $\mathrm{mRCC}$ patients (11). However, 
Table I. Patient characteristics

\begin{tabular}{|c|c|}
\hline Median age (years, range) & $62(41-83)$ \\
\hline \multicolumn{2}{|l|}{ Gender $(\%)$} \\
\hline Male & $32(71.4)$ \\
\hline Female & $12(28.6)$ \\
\hline \multicolumn{2}{|l|}{ Nephrectomy (\%) } \\
\hline Yes & $37(88.1)$ \\
\hline No & $5(11.9)$ \\
\hline \multicolumn{2}{|c|}{ First-line systemic therapy (\%) } \\
\hline Cytokine & $14(33.3)$ \\
\hline Sunitinib & $28(66.7)$ \\
\hline \multicolumn{2}{|l|}{ IMDC risk classification (\%) } \\
\hline Favorable & $10(23.8)$ \\
\hline Intermediate & $23(54.8)$ \\
\hline Poor & 9 (21.4) \\
\hline \multicolumn{2}{|l|}{$\mathrm{C}$-reactive protein $(\%)$} \\
\hline$<0.8 \mathrm{mg} / \mathrm{dL}$ & $27(64.3)$ \\
\hline $0.8 \mathrm{mg} / \mathrm{dL} \leq$ & $15(35.7)$ \\
\hline \multicolumn{2}{|c|}{ Number of lung metastases (\%) } \\
\hline$\leq 3$ & $23(54.8)$ \\
\hline $4 \leq$ & $19(45.2)$ \\
\hline \multicolumn{2}{|l|}{ Side of lung metastases $(\%)$} \\
\hline Unilateral lung & $24(66.7)$ \\
\hline Bilateral lungs & $18(33.3)$ \\
\hline \multicolumn{2}{|c|}{ Histology of primary tumor $(\%)$} \\
\hline Clear cell cancer & $38(90.5)$ \\
\hline Non-clear cell cancer & $4(9.5)$ \\
\hline \multicolumn{2}{|l|}{ Sarcomatoid feature $(\%)$} \\
\hline Positive & $6(14.3)$ \\
\hline Negative & $36(85.7)$ \\
\hline
\end{tabular}

IMDC: International Renal Cell Carcinoma Database Consortium.

there have been several studies investigating the utility of sorafenib for mRCC patients with specific characteristics, such as elderly age and impaired renal function, considering the attaractive features of this agent, including the impact on overall survival comparable to other targeted agents and relatively favorable safety profiles (11-13). In this study, we enrolled a total of $42 \mathrm{mRCC}$ patients with metastases solely to the lung who received sorafenib following the failure of first-line systemic therapy and retrospectively reviewed the clinical outcomes of these patients, in order to clarify the significance of sorafenib in this cohort of patients.

\section{Patients and Methods}

Patients. The design of the present study was approved by the Research Ethics Committee of our institution, and the need to obtain informed consent to be involved in this study from all patients was waived because of its retrospective design. This was conducted as a retrospective study reviewing clinicopathological data from a total of 42 consecutive Japanese RCC patients who were diagnosed with metastases solely to the lung after the failure of first-line systemic therapy and subsequently received sorefenib as the second-line agent between August 2008 and September 2016 in a routine clinical setting at our Institution. Of the 42 patients, 5 who did not

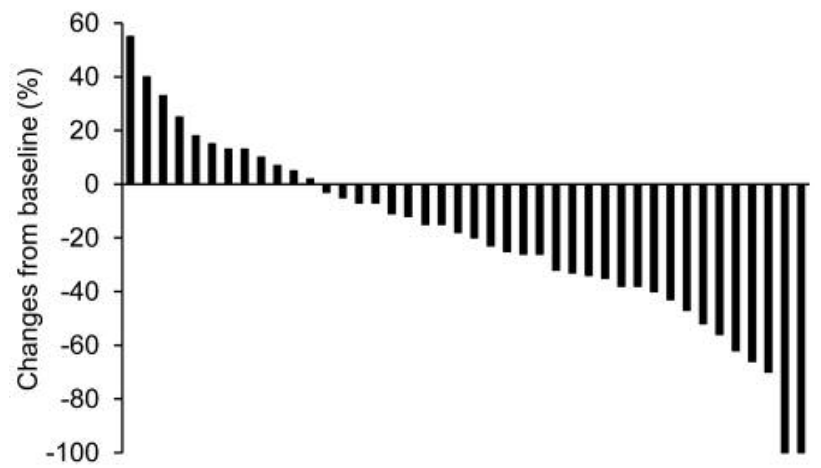

Figure 1. Maximal percent changes in the target tumor size from the baseline in 42 renal cell carcinoma patients with metastases solely to the lung who received second-line systemic treatment with sorafenib.

undergo surgical resection of the primary tumor underwent biopsies of the primary lesion to obtain histopathological findings; thus, all 42 were pathologically diagnosed with primary RCC.

Administration of sorafenib. In this series, sorafenib was initially administered to all included patients according to the standard dosing schedule reported by Escudier et al.; that is, they orally received 400 mg of sorafenib twice daily on a continuous dosing schedule (5). However, dose modification of sorafenib was permitted based on the severity of AE according to the product label.

Evaluation. As baseline assessments at the start of second-line therapy with sorafenib, the performance status (PS) and risk classification were evaluated by the Karnofsky PS scale and International Renal Cell Carcinoma Database Consortium (IMDC) system (14), respectively. Prior to the initiation of treatment with sorafenib, all patients received radiological evaluations by computed tomography (CT) of the brain, chest and abdomen and/or radionuclide bone scan. As a rule, tumor measurements were performed by CT every 6 to 12 weeks after the introduction of sorafenib. During treatment with sorafenib, responses and AEs were evaluated by the treating physician based on the Response Evaluation Criteria in Solid Tumors v.1.1 and National Cancer Institute Common Terminology Criteria for Adverse Events version 3.0, respectively. Laboratory data associated with bone marrow, renal and liver functions as well as inflammatory status were measured in each patient by standard clinical testing methods every 6 to 12 weeks.

Statistical analysis. Statview 5.0 software (Abacus Concepts, Inc., Berkley, CA, USA) was used for all statistical examinations and a $p$-value $<0.05$ was considered statistically significant. The PFS and OS rates were assessed by the Kaplan-Meier method. The prognostic significance of certain parameters was evaluated employing the Cox proportional hazards regression model.

\section{Results}

Characteristics of included patients. The clinicopathological characteristics of the 42 patients included in this study are summarized in Table I. Of these 42 patients, 14 (33.3\%) and 

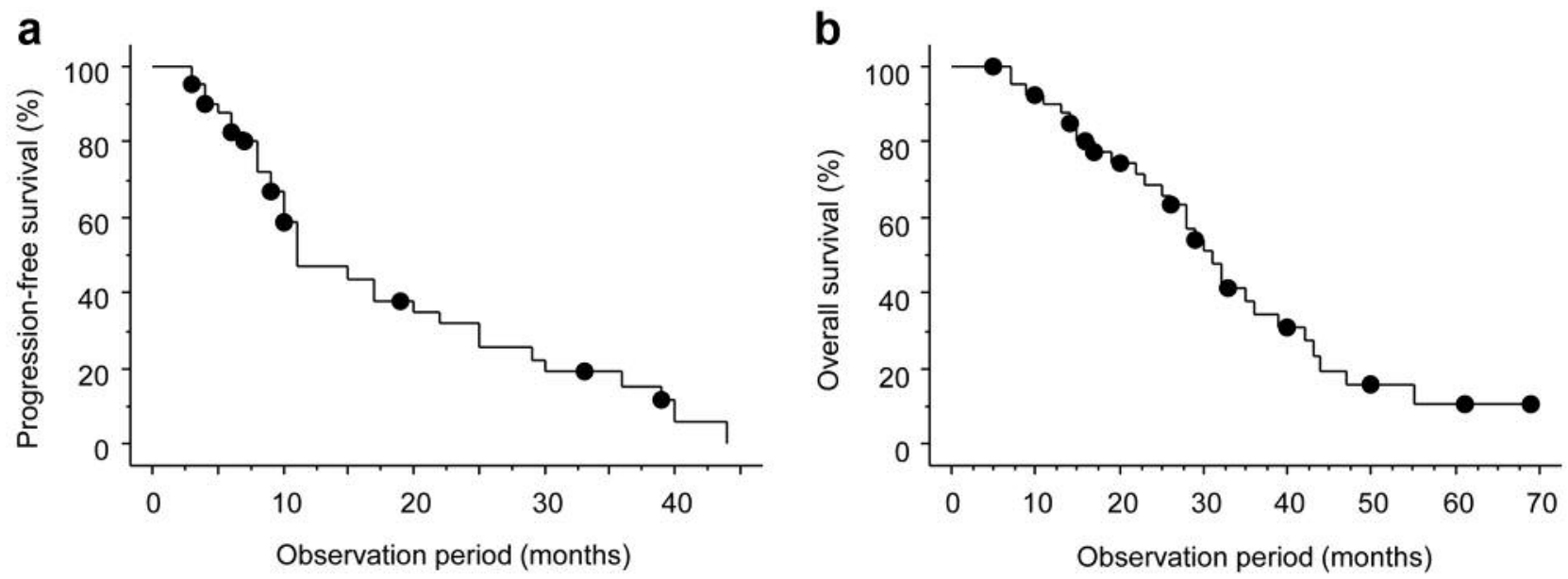

Figure 2. Progression-free survival (PFS) of the 42 renal cell carcinoma (RCC) patients with metastases solely to the lung after receiving secondline systemic treatment with sorafenib (a). Overall survival (OS) of the 42 renal cell carcinoma (RCC) patients with metastases solely to the lung after receiving second-line systemic treatment with sorafenib (b).

$28(66.7 \%)$ received cytokine therapy and sunitinib, respectively, as first-line systemic treatment. Following the failure of first-line therapy, all 42 patients were radiologically diagnosed with metastases solely to the lung, and sorafenib was subsequently administered as the second-line systemic agent.

Oncological outcomes. The median period of treatment with sorafenib in these patients was 13.2 months (range $=2-39$ ), and dose-reduction was done in 27 patients $(64.3 \%)$. Of the 42 patients, $38(90.5 \%)$ and $4(9.5 \%)$ stopped receiving sorafenib due to disease progression and intolerable AEs, respectively. As the best response to sorafenib in the 42 patients, $2(4.8 \%), 14(33.3 \%)$ and $22(52.4 \%)$ showed a complete response, partial response and stable disease, respectively, for at least 6 weeks; however, the remaining 4 $(9.5 \%)$ were judged to have progressive disease. Therefore, the objective response rate (ORR) and clinical benefit rate in this series were 38.1 and $90.5 \%$, respectively. The maximum reduction from the baseline of the target tumors in the 42 patients is shown in Figure 1.

PFS and OS of the 42 patients after introducing sorafenib were then evaluated. As shown in Figure 2, the median PFS and $O S$ in this series were 10.3 and 30.2 months, respectively. Furthermore, the impacts of several clinicopathological parameters on PFS and OS in these 42 patients were investigated (Table II). Univariate analyses identified the following significant prognostic indicators: IMDC classification ( $p=0.012)$ and $C$-reactive protein (CRP) level ( $p=0.0083)$ for PFS; IMDC classification $(p=0.018)$, CRP level $(p=0.0073)$ and sarcomatoid feature $(p=0.037)$ for OS. Multivariate analyses of these significant prognostic indicators were subsequently conducted, and the following parameters were suggested to have independent prognostic impacts: CRP level $(p=0.024)$ for PFS; IMDC classification $(p=0.042)$ and CRP level $(p=0.022)$ for OS.

Profiles of AEs. AEs associated with the use of sorafenib are presented in Table III. All patients experienced AEs, and the common AEs were hand-foot syndrome, hypertension and diarrhea, which occurred in 22 (52.4\%), 17 (40.5\%) and 13 $(31.0 \%)$, respectively; however, AEs corresponding to $\geq$ grade 3 developed in only $16(38.1 \%)$, and there was no case of treatment-related death.

\section{Discussion}

Due to the prevalence of potential TKIs in real-world clinical practice, particularly that of axitinib, shown to significantly prolong PFS in previously treated $\mathrm{mRCC}$ patients compared with sorafenib (8-10), it has become uncommon to widely introduce sorefenib for mRCC patients in either a first- or second-line setting (11). This trend has become more marked since the recent approval of immune checkpoint inhibitors, such as nivolumab and ipilimumab, for mRCC patients as both first- and second-line therapies (15). To date, however, there have been several studies suggesting the significant role of sorafenib for treating mRCC patients with specific characteristics (11-13). For example, Tatsugami et al. reported that sorafenib in patients with an estimated glomerular filtration rate of $<45$ and $\geq 45 \mathrm{ml} / \mathrm{min} / 1.73 \mathrm{~m}^{2}$ showed similar efficacy and safety (12), while Procopio et al. analyzed the Sorafenib RCC Integrated Database according to age $(<55,55-64,65-74$, or $\geq 75$ years), and showed that sorafenib was well-tolerated regardless of age (13). Considering these findings, we focused 
Table II. Univariate and multivariate analyses of associations between various parameters with progression-free and overall survivals.

\begin{tabular}{|c|c|c|c|c|c|c|c|c|}
\hline \multirow[b]{3}{*}{ Variables } & \multicolumn{4}{|c|}{ Progression-free survival } & \multicolumn{4}{|c|}{ Overall survival } \\
\hline & \multicolumn{2}{|c|}{ Univariate analysis } & \multicolumn{2}{|c|}{ Multivariate analysi } & \multicolumn{2}{|c|}{ Univariate analysis } & \multicolumn{2}{|c|}{ Multivariate analysis } \\
\hline & Hazard ratio & $p$-Value & Hazard ratio & $p$-Value & Hazard ratio & $p$-Value & Hazard ratio & $p$-Value \\
\hline Age (years) $(<60$ versus $\geq 60)$ & 0.78 & 0.64 & - & - & 0.56 & 0.23 & - & - \\
\hline Gender (male versus female) & 1.32 & 0.41 & - & - & 1.44 & 0.42 & - & - \\
\hline Prior nephrectomy (yes versus no) & 0.45 & 0.1 & - & - & 0.43 & 0.089 & - & - \\
\hline First-line therapy (cytokine versus sunitinib) & 1.13 & 0.47 & - & - & 1.17 & 0.48 & - & - \\
\hline IMDC risk classification (poor versus others) & 3.89 & 0.012 & 1.72 & 0.089 & 3.54 & 0.018 & 2.78 & 0.042 \\
\hline C-reactive protein $(\mathrm{mg} / \mathrm{dL})(<0.8$ versus $\geq 0.8)$ & 3.92 & 0.0083 & 3.19 & 0.024 & 4.07 & 0.0073 & 3.38 & 0.022 \\
\hline Number of lung metastasis ( $\leq 3$ versus $\geq 4)$ & 0.68 & 0.52 & - & - & 0.61 & 0.4 & - & - \\
\hline Side of lung metastasis (unilateral versus bilateral) & 0.57 & 0.48 & - & - & 0.53 & 0.18 & - & - \\
\hline Histological subtype (CCC versus non-CCC) & 0.53 & 0.35 & - & - & 0.57 & 0.29 & - & - \\
\hline Sarcomatoid feature (yes versus no) & 1.8 & 0.12 & - & - & 2.92 & 0.0037 & 1.77 & 0.18 \\
\hline
\end{tabular}

IMDC: International Renal Cell Carcinoma Database Consortium; CCC: clear cell cancer.

on the efficacy of sorafenib as a second-line systemic agent for mRCC patients with metastases solely to the lung, who are generally regarded as having a comparatively favorable prognosis, and retrospectively assessed the comprehensive clinical outcomes in these patients.

The ORR of sorafenib in this series, consisting of patients with metastases solely to the lung, was $38.1 \%$, which is higher than those of previous studies $(5,11,16-18)$. The ORRs in the global phase III TARGET trial and Japanese phase II trial were 12 and $10 \%$, respectively $(5,16)$. In addition, ORRs of sorafenib in a large and diverse population of $\mathrm{mRCC}$ patients treated in routine clinical practice were reported to be approximately $20-25 \%(17,18)$. Akaza et al. conducted a large-scale prospective registration study of Japanese mRCC patients receiving sorafenib, and showed a finding similar to that of the present study; that is, a favorable response of lung metastases to sorafenib (31.2\%) was observed compared with metastases to other organs (18). However, a recently performed systematic review and metaanalysis revealed that significant differences in ORRs were found in favor of other targeted agents compared with sorafenib, irrespective of therapeutic lines (11). Collectively, these findings suggest that it is a suitable strategy for RCC patients with metastases solely to the lung to introduce sorafenib as second-line therapy to achieve a favorable response after the failure of first-line systemic therapy.

To date, there have been several studies assessing prognostic outcomes in mRCC patients treated with sorafenib $(5,11,16$, 19, 20). For example, PFS and OS in the TARGET trial were 5.5 and 17.8 months, respectively $(5,19)$, while those in the Japanese phase II trial were 7.9 and 25.3 months, respectively $(16,20)$. In the 42 RCC patients with metastases solely to the lung included in this study, the median PFS and OS were 10.6
Table III. Adverse events associated with sorafenib.

\begin{tabular}{lcc}
\hline Adverse events $(\%)$ & All grades & Grade 3 \\
\hline All adverse events & $42(100)$ & $16(38.1)$ \\
Hand-foot syndrome & $22(52.4)$ & $5(11.9)$ \\
Hypertension & $17(40.5)$ & $4(9.5)$ \\
Diarrhea & $13(31.0)$ & $2(4.8)$ \\
Rash & $12(28.6)$ & $1(2.4)$ \\
Alopecia & $9(21.4)$ & $0(0)$ \\
Liver dysfunction & $9(21.4)$ & $5(11.9)$ \\
Appetite loss & $6(14.3)$ & $1(2.4)$ \\
Mucositis & $5(11.9)$ & $0(0)$ \\
Dysphonia & $5(11.9)$ & $0(0)$ \\
\hline
\end{tabular}

and 30.2 months, respectively, which are more favorable than those of previous studies. Furthermore, these prognostic outcomes, particularly OS, are comparable or even superior to those in mRCC patients receiving other targeted agents (1-3). In fact, sorafenib has been frequently used as the standard comparator for clinical trials testing the efficacies of other targeted agents, such as axitinib and temsirolimus, in mRCC patients, and the findings of these trials consistently demonstrated that sorafenib is likely to have a more favorable effect on OS than on PFS compared with other targeted agents $(10,11,21)$. Taken together, if metastatic spread is limited to the lung alone after the failure of first-line systemic therapy, the prognosis of mRCC patients could be expected to be favorably controlled by the administration of sorafenib.

Although lung metastases have been shown to respond well to targeted agents (18), it is still of interest to identify reliable prognostic factors in RCC patients with metastases 
solely to the lung receiving sorafenib as second-line systemic therapy. In this series, multivariate analyses revealed the following independent prognostic parameters: CRP level for PFS, and IMDC classification and CRP level for OS. The prognostic significance of these factors was consistently identified in several previous studies, including those focusing on second-line targeted therapy for $\operatorname{mRCC}(14,18$, 22-24). Accordingly, based on the findings of this study, even in patients with metastases solely to the lung, we should consider introducing standard second-line agents rather than sorafenib for patients classified into a poor risk group and/or those with an elevated CRP level.

It is important to perform detailed evaluation of the toxicity profile of sorafenib observed in this series. All patients included in this study experienced some kind of $\mathrm{AE}$, and the frequently observed AEs were hand-foot syndrome, hypertension and diarrhea, with each occurring in $>30 \%$ of patients; however, AEs corresponding to $\geq$ grade 3 occurred in $<40 \%$ of patients, there was no case of sorafenibassociated death, and all AEs that developed in this series were manageable with dose reduction and/or standard conservative treatments. Since Japanese patients have been reported to be more sensitive to targeted agents against RCC than Western populations according to the findings of clinical trials, including those associated with sorafenib (5, $8,16,25)$, the present $\mathrm{AE}$ profile suggests the favorable tolerability of sorafenib compared with other TKIs, which may contribute to maintaining the clinical role of this agent.

Herein, we would like to describe several limitations of this study. Firstly, this was a retrospective study including an insufficient number of patients; therefore, it is difficult to draw definitive conclusions, particularly regarding prognostic issues, based on the findings of this study. Secondly, treatment with sorafenib was initiated in most of the patients included in this study in the early era of targeted therapy; therefore, it was not possible for these patients to be treated with some of the currently available agents against mRCC, including immune checkpoint inhibitors. Finally, although this study was carried out focusing on RCC patients with metastases solely to the lung, there might be other specific cohorts who could benefit from treatment with sorafenib.

\section{Conclusion}

To our knowledge, this is the first study investigating the outcome of sorafenib as a second-line systemic therapy for RCC patients with metastases solely to the lung, showing encouraging data regarding the efficacy, as well as tolerability of this agent. Therefore, the findings presented in this study strongly suggest that the introduction of sorafenib could be a promising option for RCC patients with metastases solely to the lung following the failure of firstline systemic therapy.

\section{Conflicts of Interest}

The Authors have no conflict of interest to declare.

\section{Authors' Contributions}

The types of contribution by each author are as follows: Study conception and design, Hideaki Miyake; Acquisition of data, Yuto Matsushita, Hiromitsu Watanabe, Keita Tamura, Daisuke Motoyama, ToshikI Ito, Takayuki Sugiyama; Analysis and interpretation of data, Hideaki Miyake, Atsushi Otsuka; Drafting of manuscript and critical revision, Hideaki Miyake.

\section{References}

1 Bedke J, Gauler T, Grünwald V, Hegele A, Herrmann E, Hinz S, Janssen J, Schmitz S, Schostak M, Tesch H, Zastrow S and Miller K: Systemic therapy in metastatic renal cell carcinoma. World J Urol 35: 179-188, 2017. PMID: 27277600, doi: 10.1007/s00345-016-1868-5

2 Calvo E, Ravaud A and Bellmunt J: What is the optimal therapy for patients with metastatic renal cell carcinoma who progress on an initial VEGFr-TKI? Cancer Treat Rev 39: 366-374, 2013. PMID: 22832091, doi: 10.1016/j.ctrv.2012.06.010

3 Oudard S and Elaidi RT: Sequential therapy with targeted agents in patients with advanced renal cell carcinoma: optimizing patient benefit. Cancer Treat Rev 38: 981-987, 2012. PMID: 22289686, doi: 10.1016/j.ctrv.2011.12.009

4 Wilhelm S, Carter C, Lynch M, Lowinger T, Dumas J, Smith RA, Schwartz B, Simantov R and Kelley S: Discovery and development of sorafenib: a multikinase inhibitor for treating cancer. Nat Rev Drug Discov 5: 835-844, 2006. PMID: 17016424, doi: 10.1038/nrd2130

5 Escudier B, Eisen T, Stadler WM, Szczylik C, Oudard S, Siebels M, Negrier S, Chevreau C, Solska E, Desai AA, Rolland F, Demkow T, Hutson TE, Gore M, Freeman S, Schwartz B, Shan M, Simantov R and Bukowski RM: Sorafenib in advanced clearcell renal-cell carcinoma. N Engl J Med 356: 125-134, 2007. PMID: 17215530, doi: 10.1056/NEJMoa060655

6 Stadler WM, Figlin RA, McDermott DF, Dutcher JP, Knox JJ, Miller WH Jr, Hainsworth JD, Henderson CA, George JR, Hajdenberg J, Kindwall-Keller TL, Ernstoff MS, Drabkin HA, Curti BD, Chu L, Ryan CW, Hotte SJ, Xia C, Cupit L and Bukowski RM: Safety and efficacy results of the advanced renal cell carcinoma sorafenib expanded access program in North America. Cancer 116: 1272-1280, 2010. PMID: 20082451, doi: 10.1002/cncr.24864

7 Beck J, Procopio G, Bajetta E, Keilholz U, Negrier S, Szczylik C, Bokemeyer C, Bracarda S, Richel DJ, Staehler M, Strauss UP, Mersmann S, Burock K and Escudier B: Final results of the European Advanced Renal Cell Carcinoma Sorafenib (EUARCCS) expanded-access study: a large open-label study in diverse community settings. Ann Oncol 22: 1812-1823, 2011. PMID: 21324953, doi: 10.1093/annonc/mdq651

8 Motzer RJ, Hutson TE, Tomczak P, Motzer RJ, Hutson TE, Tomczak P, Michaelson MD, Bukowski RM, Rixe O, Oudard S, Negrier S, Szczylik C, Kim ST, Chen I, Bycott PW, Baum CM and Figlin RA: Sunitinib versus interferon alfa in metastatic renal-cell carcinoma. N Engl J Med 356: 115-124, 2007. PMID: 17215529, doi: 10.1056/NEJMoa065044 
9 Motzer RJ, Hutson TE, Cella D, Reeves J, Hawkins R, Guo J, Nathan P, Staehler M, de Souza P, Merchan JR, Boleti E, Fife K, Jin J, Jones R, Uemura H, De Giorgi U, Harmenberg U, Wang J, Sternberg CN, Deen K, McCann L, Hackshaw MD, Crescenzo R, Pandite LN and Choueiri TK: Pazopanib versus sunitinib in metastatic renal-cell carcinoma. N Engl J Med 369: 722-731, 2013. PMID: 23964934, doi: 10.1056/ NEJMoa1303989

10 Rini BI, Escudier B, Tomczak P, Kaprin A, Szczylik C, Hutson TE, Michaelson MD, Gorbunova VA, Gore ME, Rusakov IG, Negrier S, Ou YC, Castellano D, Lim HY, Uemura H, Tarazi J, Cella D, Chen C, Rosbrook B, Kim S and Motzer RJ: Comparative effectiveness of axitinib versus sorafenib in advanced renal cell carcinoma (AXIS): a randomised phase 3 trial. Lancet 378: 1931-1939, 2011. PMID: 22056247, doi: 10.1016/S0140-6736(11)61613-9

11 Iacovelli R, Verri E, Cossu Rocca M, Aurilio G, Cullurà D, Santoni M, de Cobelli $\mathrm{O}$ and Nolé F: Is there still a role for sorafenib in metastatic renal cell carcinoma? A systematic review and meta-analysis of the effectiveness of sorafenib over other targeted agents. Crit Rev Oncol Hematol 99: 324-331, 2016. PMID: 26818051, doi: 10.1016/j.critrevonc.2016.01.014

12 Tatsugami K, Oya M, Kabu K and Akaza H: Efficacy and safety of sorafenib for advanced renal cell carcinoma: real-world data of patients with renal impairment. Oncotarget 9: 19406-19414, 2018. PMID: 29721212, doi: 10.18632/oncotarget.24779

13 Procopio G, Bellmunt J, Dutcher J, Bracarda S, Knox J, Brueckner A, Molnar I, Escudier B and Hutson TE: Sorafenib tolerability in elderly patients with advanced renal cell carcinoma: results from a large pooled analysis. Br J Cancer 108: 311-318, 2013. PMID: 23322192, doi: 10.1038/bjc.2012.543

14 Heng DY, Xie W, Regan MM, Warren MA, Golshayan AR, Sahi C, Eigl BJ, Ruether JD, Cheng T, North S, Venner P, Knox JJ, Chi KN, Kollmannsberger C, McDermott DF, Oh WK, Atkins MB, Bukowski RM, Rini BI and Choueiri TK: Prognostic factors for overall survival in patients with metastatic renal cell carcinoma treated with vascular endothelial growth factortargeted agents: results from a large, multicenter study. J Clin Oncol 27: 5794-5799, 2009. PMID: 19826129, doi: 10.1200/JCO.2008.21.4809

15 Alsharedi $\mathrm{M}$ and Katz $\mathrm{H}$ : Check point inhibitors a new era in renal cell carcinoma treatment. Med Oncol 35: 85, 2018. PMID: 29728867, doi: 10.1007/s12032-018-1147-y

16 Akaza H, Tsukamoto T, Murai M, Nakajima K and Naito S: Phase II study to investigate the efficacy, safety, and pharmacokinetics of sorafenib in Japanese patients with advanced renal cell carcinoma. Jpn J Clin Oncol 37: 755-762, 2007. PMID: 17951335, doi: 10.1093/jjco/hym095

17 Jäger D, Ma JH, Mardiak J, Ye DW, Korbenfeld E, Zemanova M, Ahn H, Guo J, Leonhartsberger N, Stauch K, Böckenhoff A, $\mathrm{Yu} \mathrm{J}$ and Escudier B: Sorafenib treatment of advanced renal cell carcinoma patients in daily practice: the large international PREDICT study. Clin Genitourin Cancer 13: 156-164.e1, 2015. PMID: 25444666, doi: 10.1016/j.clgc.2014.07.007

18 Akaza H, Oya M, Iijima M, Hyodo I, Gemma A, Itoh H, Adachi M, Okayama Y, Sunaya T and Inuyama L: A large-scale prospective registration study of the safety and efficacy of sorafenib tosylate in unresectable or metastatic renal cell carcinoma in Japan: results of over 3200 consecutive cases in post-marketing all-patient surveillance. Jpn J Clin Oncol 45: 953-962, 2015. PMID: 26206897, doi: 10.1093/jjco/hyv099
19 Escudier B, Eisen T, Stadler WM, Szczylik C, Oudard S, Staehler M, Negrier S, Chevreau C, Desai AA, Rolland F, Demkow T, Hutson TE, Gore M, Anderson S, Hofilena G, Shan M, Pena C, Lathia C and Bukowski RM: Sorafenib for treatment of renal cell carcinoma: Final efficacy and safety results of the phase III treatment approaches in renal cancer global evaluation trial. J Clin Oncol 27: 3312-3318, 2009. PMID: 19451442, doi: 10.1200/JCO.2008.19.5511

20 Naito S, Tsukamoto T, Murai M, Fukino K and Akaza H: Overall survival and good tolerability of long-term use of sorafenib after cytokine treatment: final results of a phase II trial of sorafenib in Japanese patients with metastatic renal cell carcinoma. BJU Int 108: 1813-1819, 2011. PMID: 21481133, doi: 10.1111/j.1464-410X.2011.10281.X

21 Hutson TE, Escudier B, Esteban E, Bjarnason GA, Lim HY, Pittman KB, Senico P, Niethammer A, Lu DR, Hariharan S and Motzer RJ: Randomized phase III trial of temsirolimus versus sorafenib as second-line therapy after sunitinib in patients with metastatic renal cell carcinoma. J Clin Oncol 32: 760-767, 2014. PMID: 24297950, doi: 10.1200/JCO.2013.50.3961

22 Beuselinck B, Vano YA, Oudard S, Wolter P, De Smet R, Depoorter L, Teghom C, Karadimou A, Zucman-Rossi J, Debruyne PR, Van Poppel H, Joniau S, Lerut E, Strijbos M, Dumez H, Paridaens R, Van Calster B and Schöffski P: Prognostic impact of baseline serum $\mathrm{C}$-reactive protein in patients with metastatic renal cell carcinoma (RCC) treated with sunitinib. BJU Int 114: 81-89, 2014. PMID: 24215209, doi: 10.1111/bju.12494

23 Signorovitch JE, Vogelzang NJ, Pal SK, Lin PL, George DJ, Wong MK, Liu Z, Wang X, Culver K, Scott JA and Jonasch E: Comparative effectiveness of second-line targeted therapies for metastatic renal cell carcinoma: synthesis of findings from two multi-practice chart reviews in the United States. Curr Med Res Opin 30: 2343-2353, 2014. PMID: 25105304, doi: $10.1185 / 03007995.2014 .949645$

24 Miyake H, Harada KI, Ozono S and Fujisawa M: assessment of efficacy, safety, and quality of life of 124 patients treated with axitinib as second-line therapy for metastatic renal-cell carcinoma: Experience in real-world clinical practice in Japan. Clin Genitourin Cancer 15: 122-128, 2017. PMID: 27473522, doi: 10.1016/j.clgc.2016.06.019

25 Uemura H, Shinohara N, Yuasa T, Tomita Y, Fujimoto H, Niwakawa M, Mugiya S, Miki T, Nonomura N, Takahashi M, Hasegawa Y, Agata N, Houk B, Naito S and Akaza H: A phase II study of sunitinib in Japanese patients with metastatic renal cell carcinoma: insights into the treatment, efficacy and safety. Jpn J Clin Oncol 40: 194-202, 2010. PMID: 19897852, doi: 10.1093/jjco/hyp 146
Received December 26, 2018

Revised January 15, 2019

Accepted January 17, 2019 